\title{
Experimental and Modeling Studies on the Prediction of Gas Hydrate Formation
}

\author{
Jian-Yi Liu, ${ }^{1}$ Jing Zhang, ${ }^{2,3}$ Yan-Li Liu, ${ }^{4}$ Xiao-Hua Tan, ${ }^{1}$ and Jie Zhang ${ }^{5}$ \\ ${ }^{1}$ State Key Laboratory of Oil and Gas Reservoir Geology and Exploitation, Southwest Petroleum University, \\ Xindu Road 8, Chengdu 610500, China \\ ${ }^{2}$ Sulige Gas Field Research Center, Changqing Oilfield Company, Xian 710018, China \\ ${ }^{3}$ National Engineering Laboratory for Exploration and Development of Low Permeability Oil and Gas Fields, Xian 710018, China \\ ${ }^{4}$ Drilling and Producing Technology Research Institute, Liaohe Oilfield, Panjin 124010, China \\ ${ }^{5}$ Tahe Oil Production Plant No.1, Sinopec Northwest Oilfield Branch, Luntai 841600, China \\ Correspondence should be addressed to Xiao-Hua Tan; xiaohua-tan@163.com
}

Received 30 July 2014; Accepted 21 October 2014

Academic Editor: Hasan Uslu

Copyright ( 2015 Jian-Yi Liu et al. This is an open access article distributed under the Creative Commons Attribution License, which permits unrestricted use, distribution, and reproduction in any medium, provided the original work is properly cited.

On the base of some kinetics model analysis and kinetic observation of hydrate formation process, a new prediction model of gas hydrate formation is proposed. The analysis of the present model shows that the formation of gas hydrate not only relevant with gas composition and free water content but also relevant with temperature and pressure. Through contrast experiment, the predicted result of the new prediction method of gas hydrate crystallization kinetics is close to measured result, it means that the prediction method can reflect the hydrate crystallization accurately.

\section{Introduction}

During the exploitation process, the gas well sometimes closed because of plugging in wellbore or surface pipeline which is caused by gas hydrate [1-4]. In order to solve a series of plugging problems caused by hydrate in oil field and develop natural gas hydrate resources more effectively and utilize hydrate technology more reasonably, the research on natural gas hydrate crystallization kinetics mechanism becomes very necessary $[5,6]$.

An operation step of crystal nucleus growth process is an important factor need to research in the study of crystallization kinetics [7]. In different system, many factors can be used to control crystal nucleus growth process, such as diffusion, heat transfer, stirring rate, reaction kinetics, and heat exchange rate on surface of crystal [8-10]. In view of the above factors, many researchers propose the crystallization kinetics model which describes the nucleation based on mass transfer theory, crystallization theory, and two-film gasliquid mass transfer theory $[11,12]$.
The generation of hydrate is actually the nucleation and crystal growth process. Kinetics of hydrate formation is related to generation rate, pressure, temperature, and so forth. The process can be clearly divided into three steps: at first the generation of crystal nucleus with critical radius, then solid crystal nucleus growth, and at last the components transfer to solid-liquid interface of nuclear at aggregation state [13-15].

Many factors affect the generation of natural gas hydrate; there are three main points. (1) When the gas temperature is equal to or lower than the water dew point and is accompanied with free water or liquid water, then hydrate formed. (2) In condition of certain pressure and gas composition, the temperature is lower than the hydrate formation temperature; then hydrate formed. (3) The high operating pressure will rise the hydrate formation temperature [16].

This paper developed a new prediction method of gas hydrate crystallization kinetics according to the shrinkage bubble model and considering the variation of pressure with time at the same time, to establish a new method for the prediction of natural gas hydrate. 


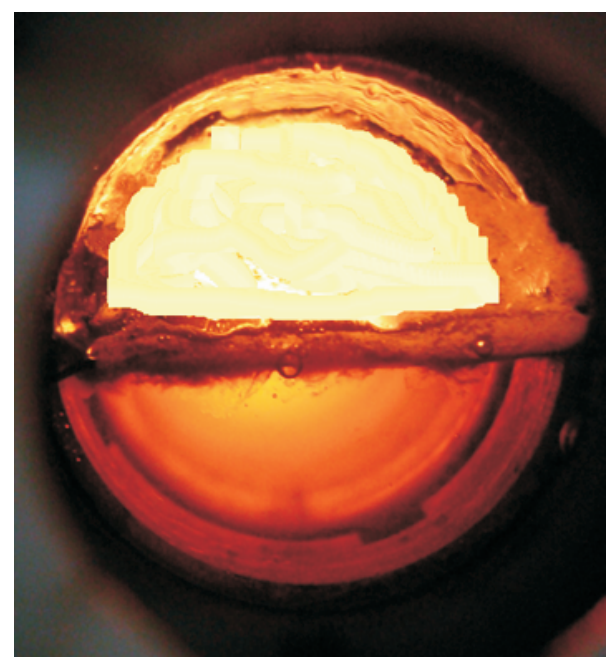

FIGURE 1: Kinetic observation of hydrate formation process.

\section{Model}

2.1. Hydrate Growth Dynamic. During the hydrate formation process there is transfer phenomena in the hydrate-gas-water [17-19]. The kinetic observation of hydrate formation process is shown in Figure 1. From the figure we can know that at first hydrate mainly gathered at the air-water interface layer; when the temperature is lower than the hydrate phase equilibrium temperature, hydrate nucleation formed quickly by gas and water molecules inside the bubble $[20,21]$. The generation process of crystal nucleus is the process that water diffuse into a bubble and gas in bubble diffuse out of bubble; finally the bubble in hydrate gradually reduced and even disappeared then hydrate crystals formed. Experiments show that the hydrate formation process is controlled by the transmission rate of gas and water molecules, through the establishment of hydrate formation kinetics method can describe the generation process [22].

2.2. Shrinkage Bubble Kinetics. Through the hydrate growth kinetic observation we can know that during the growth process of hydrate crystals the bubbles transform into hydrate; the process is shown in Figure 2. In Figure 2, the exterior is water, the internal is gas, and the ring is hydrate.

Hydrate volume in hydrate crystals is

$$
V_{h}=\frac{4}{3} \pi\left(r_{h}^{3}-r_{b}^{3}\right)
$$

where $r_{h}$ is outer radius of hydrate, $r_{b}$ is bubble radius, and $V_{h}$ is hydrate volume in hydrate crystals.

The growth rate of hydrate is

$$
\frac{d V_{h}}{d t}=4 \pi\left[r_{h}^{2} \frac{d r_{h}}{d t}-r_{b}^{2} \frac{d r_{b}}{d t}\right]
$$

During the formation process of hydrates, the chemical potential in phase equilibrium systemization is equal.

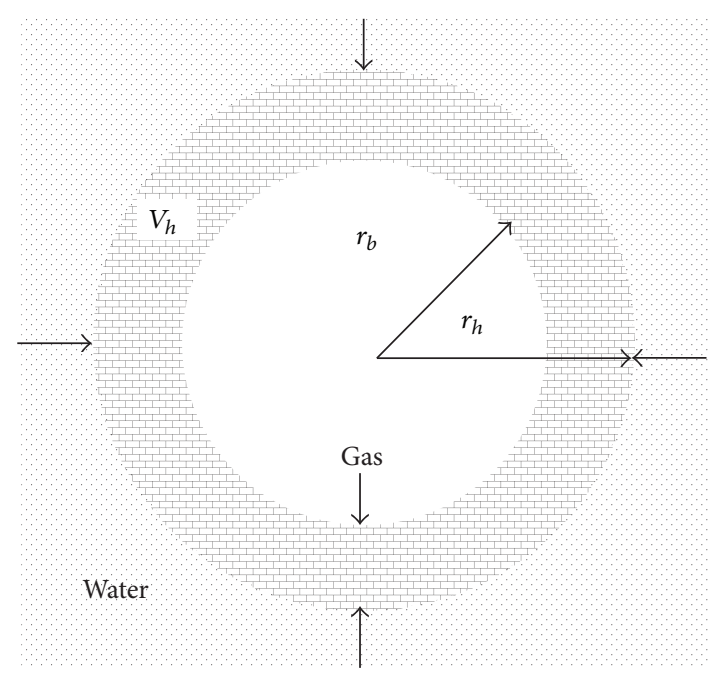

FIGURE 2: Process of a bubble transforming into hydrate.

According to gas adsorption model and the law of diffusion, the hydrate formation rate equation is obtained as follows

$$
\frac{d V_{h}}{d t}=4 \pi D \frac{r_{b} r_{h}}{r_{h}-r_{b}}\left[\frac{p_{b}-p_{d}}{p_{b}}\right],
$$

where $p_{b}$ is inner air pressure of bubble and $p_{d}$ is decomposition pressure. $D$ is the mass transfer coefficient and it can be expressed as

$$
D=\frac{\left(1-y_{d}\right) D_{h a}}{y_{d}}+v c_{d} D_{h w}
$$

where $y_{d}$ is lattice occupancy, $v$ is vacant hole numbers of each water molecule, $c_{d}$ is water solution concentration under the decomposition pressure of hydrate, $D_{h a}$ is mass transfer coefficient between hydrate and gas, and $D_{h w}$ is mass transfer coefficient between hydrate and water.

Supposing the gas in bubble and hydrate is ideal gas, then

$$
V_{b} p_{b}+V_{h} p_{h a} \phi=V_{b 0} p_{b 0}
$$

where $\phi$ is porosity and $V_{b}$ is bubble volume. $p_{h a}$ is the pressure when the gas density in bubble is equal to the gas density in hydrate, $\rho_{\text {ha }}$, which can be expressed as

$$
p_{h a}=\frac{\rho_{h a} R_{g} T}{M} .
$$

Because the reaction is controlled by mass transfer, so the change rate of hydrate volume is

$$
\omega_{h}=-\frac{\left[d V_{b} / d t+\left(1-d_{h a}\right)\left(d V_{b} / d t\right)\right]}{\left(V_{b}+V_{h}\right)}
$$


From the experiment we can know that hydrate is plastic materials, so

$$
p_{1}-p_{b}=\frac{4}{3} K_{c}(\omega-c \omega)
$$

where $\omega$ is compressibility of vacant hole.

Then forward formula becomes

$$
\begin{gathered}
p_{1}-p_{b}=\frac{4}{3} K_{c} \omega_{h}\left[\frac{r_{h}^{3}-r_{b}^{3}}{r_{h}^{3}}\right], \\
\frac{d V_{b}}{d t}=-\left[\frac{V_{b}}{p_{b}} \frac{d p_{b}}{d t}+\frac{p_{h a} \phi}{p_{b}} \frac{d V_{h}}{d t}\right] .
\end{gathered}
$$

By comprehensive analysis

$$
r_{h}=\left[\frac{3\left(V_{b 0} p_{b 0}-V_{b} p_{b}\right)}{4 \pi p_{h a} \phi}+r_{b}^{3}\right]^{1 / 3}
$$

Dividing the formation process of gas hydrate into many small blocks of time and assuming that the pressure in bubbles is unchanged mean that $p_{b}$ is a constant. From the above formulas the relationship that $r_{b}$ changes with time can be known; then the rate of hydrate formation can be known, finally:

$$
\begin{aligned}
p_{1}-p_{b}= & \frac{4}{3} K_{c} \frac{r_{h}^{3}-r_{b}^{3}}{r_{h}^{3}} \\
& \times\left(p_{b}\left[\frac{\left(p_{h a} \phi / p_{b}-1+d_{h a}\right) 4 \pi D r_{b} r_{h}}{\left(r_{h}-r_{b}\right)\left(p_{b}-p_{d}\right) / p_{h}}\right]\right) \\
& \times\left(V_{h} p_{b}+V_{b 0} p_{b 0}-V_{h} p_{h a} \phi\right)^{-1} .
\end{aligned}
$$

From the above formulas $r_{h}$ and $r_{b}$ can be calculated. $r_{h}$ and $r_{b}$ are corresponding to $p_{b}$, and $p_{b}$ is corresponding to $t$, so the relationship between $t-p_{b}, r_{h}$, and $r_{b}$ at the whole reaction time can be calculated.

Through shrinkage bubble kinetics model the relationship between inner air pressure of bubble, outer radius of hydrate, bubble radius, and time can be known. But in the actual conditions, only environmental pressure can be detected, so it is necessary to consider relationship between environmental pressure and time to improve the shrinkage bubble kinetics.

2.3. Improvement of Shrinkage Bubble Kinetics Model. According to the constant volume substance equilibrium rule the alternation law of pressure with time can be known. In the experiments, the volume is constant which is equal to the volume of natural gas and water before hydrate formation and equal to the volume of residual gas, water, and hydrate after hydrate formation; then the pressure change. The process is shown in Figure 3.

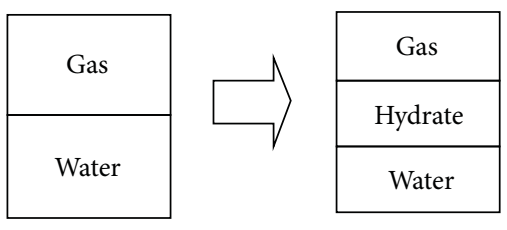

FIgURE 3: Chart of hydrate formation.

According to the principle of material balance, before hydrate formation there are

$$
\begin{gathered}
V_{\text {sum }}=V_{g}+V_{w}, \\
V_{g}=\frac{Z T p_{s c} V_{g s c}}{p_{1} T_{s c}}, \\
V_{w}=B_{w} V_{w s c}
\end{gathered}
$$

where $V_{g}$ is gas volume in the vessel, $\mathrm{m}^{3} . V_{w}$ is water volume in the vessel, $\mathrm{m}^{3} . Z$ is $Z$-factor at the vessel pressure, dimensionless. $T$ is temperature in vessel, K. $p_{1}$ is the pressure in vessel before hydrate formation, $\mathrm{MPa} . T_{\mathrm{sc}}$ is the temperature at standard state, K. $p_{\mathrm{sc}}$ is the pressure at standard state, $\mathrm{MPa}$. $V_{g s c}$ is the injected gas volume at standard state, $\mathrm{m}^{3} . V_{w s c}$ is the injected water volume at standard state, $\mathrm{m}^{3} . B_{w}$ is the volume coefficient of water, dimensionless.

After hydrate formation there are

$$
\begin{gathered}
V_{\text {sum }}=V_{g}^{\prime}+V_{w}^{\prime}+V_{h}, \\
V_{w}^{\prime}=V_{w}-V_{w c}, \\
p_{2}=\frac{N_{h} R Z T}{V_{\text {sum }}-V_{w}^{\prime}-V_{h}}, \\
V_{w c}=\frac{K N_{h}}{M_{w} \rho_{w}}, \\
N_{h}=\frac{V_{h} \rho_{h}}{M_{h}}, \\
V_{h}=n v_{h}, \\
n \leq \frac{S_{G W}}{\pi\left(3 v_{h} / 4 \pi\right)^{2 / 3}},
\end{gathered}
$$

where $V_{g}^{\prime}$ is gas volume in the vessel, $\mathrm{m}^{3} . V_{w}^{\prime}$ is water volume in the vessel, $\mathrm{m}^{3} . V_{h}$ is hydrate volume in the vessel, $\mathrm{m}^{3}$. $V_{w c}$ is consumption water volume in the vessel, $\mathrm{m}^{3} . p_{2}$ is the pressure in the vessel after hydrate formation, MPa. $N_{h}$ is molar of generated hydrate, $K$ is molar of water when generate 1 mole hydrate. $M_{w}$ is hydrate molecular weight, $\mathrm{g} / \mathrm{mol} . \rho$ is hydrate density, $\mathrm{kg} / \mathrm{m}^{3} . n$ is number of generated bubbles. $v_{h}$ is hydrate volume of each generated bubbles, $\mathrm{m}^{3}$. $S_{G W}$ is interface area between gas and water, $\mathrm{m}^{2}$. 
TABLE 1: Gas components.

\begin{tabular}{|c|c|c|c|c|c|c|c|c|c|c|}
\hline Components & $\mathrm{N}_{2}$ & $\mathrm{CO}_{2}$ & $\mathrm{C}_{1}$ & $\mathrm{C}_{2}$ & $\mathrm{C}_{3}$ & $\mathrm{iC}_{4}$ & $\mathrm{nC}_{4}$ & $\mathrm{iC}_{5}$ & $\mathrm{nC}_{5}$ & $\mathrm{C}_{6}$ \\
\hline $\begin{array}{l}\text { Content } \\
\text { (mol\%) }\end{array}$ & 2.012 & 0.2659 & 82.9622 & 9.6578 & 3.5692 & 0.3044 & 0.6639 & 0.1687 & 0.2064 & 0.1894 \\
\hline
\end{tabular}

TABLE 2: Water analysis.

\begin{tabular}{lcccccccc}
\hline Item & $\mathrm{K}^{+}$ & $\mathrm{Na}^{+}$ & $\mathrm{Ca}^{2+}$ & $\mathrm{Mg}^{2+}$ & $\mathrm{Cl}^{-}$ & $\mathrm{SO}_{4}{ }^{2-}$ & $\mathrm{HCO}_{3}^{-}$ & $\mathrm{Total} \mathrm{salinity}^{-}$ \\
\hline $\begin{array}{l}\text { Content } \\
(\mathrm{mg} / \mathrm{L})\end{array}$ & 365 & 4602 & 412 & 96 & 8007 & 535 & 460 & 14477 \\
\hline
\end{tabular}

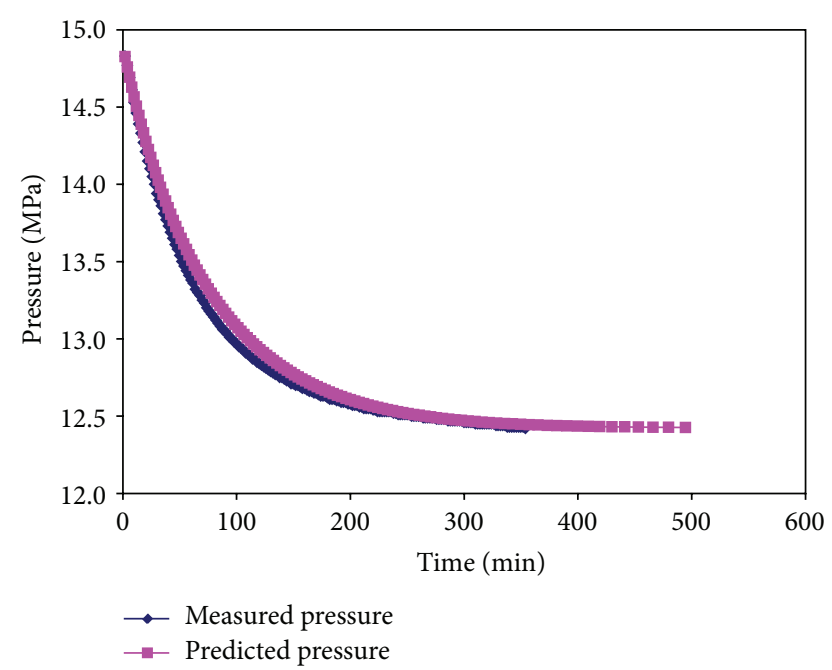

FIGURE 4: Comparison of the results of prediction method with experiment.

\section{Experiment}

3.1. Gas Sample. In this experiment using the gas sample, the content of main gas components is measured by gas chromatography, and the components are shown in Table 1.

3.2. Water Sample. In this experiment using the field water, the salinity of formation water is $14477 \mathrm{mg} / \mathrm{L}$ and $\mathrm{pH}$ value is 5.4. The analysis data of water is shown in Table 2.

Injecting $10 \mathrm{~mL}$ formation water into vessel, then injecting gas until the pressure of vessel up to $14.7 \mathrm{MPa}$, and keeping the temperature at $20^{\circ} \mathrm{C}$. It has been known that the temperature of hydrate formation is $18^{\circ} \mathrm{C}$ when the pressure is 14.7 $\mathrm{MPa}$. By decreasing the temperature to $9^{\circ} \mathrm{C}$ we can obtain the supercooled degree, that is, $9^{\circ} \mathrm{C}$. We observe and record the change of the pressure in the vessel.

\section{The Results and Discussions}

As shown in Figure 4, at first the pressure in the vessel declined rapidly; then the decrease rate become slow and steady gradually. The predicted pressure is close to measured pressure. But in the actual conditions, only environmental pressure can be detected, so it is just considered relationship between environmental pressure and time to improve the shrinkage bubble kinetics.

\section{Conclusion}

The predicted result of the new prediction method of gas hydrate crystallization kinetics is close to measured result; it means that the prediction method can reflect the hydrate crystallization accurately. In actual application the various parameters should be modified according to the practical situation.

\section{Conflict of Interests}

The authors declare that there is no conflict of interests regarding the publication of this paper.

\section{Acknowledgments}

This work was jointly supported by the National Natural Science Foundation of China (51474181) and the 2014 Australia China Natural Gas Technology Partnership Fund Top Up Scholarships.

\section{References}

[1] E. D. Sloan, Hydrate Engineering, Society of Petroleum Engineers, Richardson, Tex, USA, 2000.

[2] I. U. R. F. Makogon, Hydrates of Hydrocarbons, Pennwell Books, 1997.

[3] X.-H. Tan, X.-P. Li, and J.-Y. Liu, "Model of continuous liquid removal from gas wells by droplet diameter estimation," Journal of Natural Gas Science and Engineering, vol. 15, pp. 8-13, 2013.

[4] X.-H. Tan, J.-Y. Liu, X.-P. Li, G.-D. Zhang, and C. Tang, "A fractal model for the maximum droplet diameter in gas-liquid mist flow," Mathematical Problems in Engineering, vol. 2013, Article ID 532638, 6 pages, 2013.

[5] J. Cai, E. Perfect, C.-L. Cheng, and X. Hu, "Generalized modeling of spontaneous imbibition based on hagen-poiseuille flow in tortuous capillaries with variably shaped apertures," Langmuir, vol. 30, no. 18, pp. 5142-5151, 2014.

[6] X.-H. Tan, X.-P. Li, J.-Y. Liu, G.-D. Zhang, and L.-H. Zhang, "Analysis of permeability for transient two-phase flow in fractal porous media," Journal of Applied Physics, vol. 115, no. 11, Article ID 113502, 2014.

[7] E. D. Sloan Jr. and C. Koh, Clathrate Hydrates of Natural Gases, CRC Press, New York, NY, USA, 2007. 
[8] W. R. Parrish and J. M. Prausnitz, "Dissociation pressures of gas hydrates formed by gas mixtures," Industrial \& Engineering Chemistry Process Design and Development, vol. 11, no. 1, pp. 2635, 1972.

[9] H. Tavasoli, F. Feyzi, M. R. Dehghani, and F. Alavi, "Prediction of gas hydrate formation condition in the presence of thermodynamic inhibitors with the Elliott-Suresh-Donohue Equation of State," Journal of Petroleum Science and Engineering, vol. 77, no. 1, pp. 93-103, 2011.

[10] H. Jiang and H. Adidharma, "Prediction of hydrate dissociation conditions for alkanes in the presence of alcohol and electrolyte solutions using ion-based statistical associating fluid theory," Chemical Engineering Science, vol. 82, pp. 14-21, 2012.

[11] X.-S. Li, H.-J. Wu, and P. Englezos, "Prediction of gas hydrate formation conditions in the presence of methanol, glycerol, ethylene glycol, and triethylene glycol with the statistical associating fluid theory equation of state," Industrial \& Engineering Chemistry Research, vol. 45, no. 6, pp. 2131-2137, 2006.

[12] S. Moradi, A. Haghtalab, and A. Fazlali, "Prediction of hydrate formation conditions in the solutions containing electrolyte and alcohol inhibitors and their mixtures using UNIQUAC-NRF models," Fluid Phase Equilibria, vol. 349, pp. 61-66, 2013.

[13] H.-J. Ng and D. B. Robinson, "The measurement and prediction of hydrate formation in liquid hydrocarbon-water systems," Industrial and Engineering Chemistry Fundamentals, vol. 15, no. 4, pp. 293-298, 1976.

[14] N. Gnanendran and R. Amin, "Modelling hydrate formation kinetics of a hydrate promoter-water-natural gas system in a semi-batch spray reactor," Chemical Engineering Science, vol. 59, no. 18, pp. 3849-3863, 2004.

[15] Y. Du and T.-M. Guo, "Prediction of hydrate formation for systems containing methanol," Chemical Engineering Science, vol. 45, no. 4, pp. 893-900, 1990.

[16] T.-M. Guo, B.-H. Wu, Y.-H. Zhu, S.-S. Fan, and G.-J. Chen, "A review on the gas hydrate research in China," Journal of Petroleum Science and Engineering, vol. 41, no. 1-3, pp. 11-20, 2004.

[17] C. A. Koh, E. D. Sloan, A. K. Sum, and D. T. Wu, "Fundamentals and applications of gas hydrates," Annual Review of Chemical and Biomolecular Engineering, vol. 2, pp. 237-257, 2011.

[18] J. Javanmardi, S. Babaee, A. Eslamimanesh, and A. H. Mohammadi, "Experimental measurements and predictions of gas hydrate dissociation conditions in the presence of methanol and ethane-1,2-diol aqueous solutions," Journal of Chemical and Engineering Data, vol. 57, no. 5, pp. 1474-1479, 2012.

[19] Y. F. Makogon and R. Y. Omelchenko, "Commercial gas production from Messoyakha deposit in hydrate conditions," Journal of Natural Gas Science and Engineering, vol. 11, pp. 1-6, 2013.

[20] M. Mottahedin, F. Varaminian, and K. Mafakheri, "Modeling of methane and ethane hydrate formation kinetics based on non-equilibrium thermodynamics," Journal of Non-Equilibrium Thermodynamics, vol. 36, no. 1, pp. 3-22, 2011.

[21] K. Nasrifar and M. Moshfeghian, "A model for prediction of gas hydrate formation conditions in aqueous solutions containing electrolytes and/or alcohol," The Journal of Chemical Thermodynamics, vol. 33, no. 9, pp. 999-1014, 2001.

[22] A. Eslamimanesh, A. H. Mohammadi, and D. Richon, "Thermodynamic consistency test for experimental solubility data in carbon dioxide/methane + water system inside and outside gas hydrate formation region," Journal of Chemical \& Engineering Data, vol. 56, no. 4, pp. 1573-1586, 2011. 

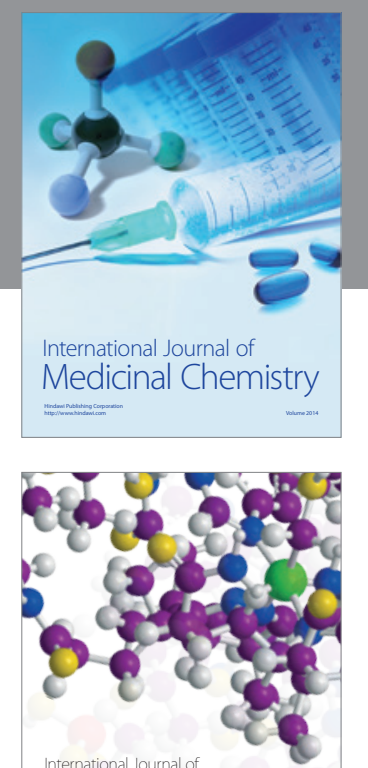

\section{Carbohydrate} Chemistry

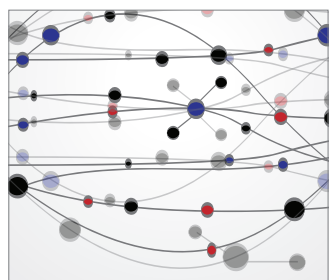

The Scientific World Journal
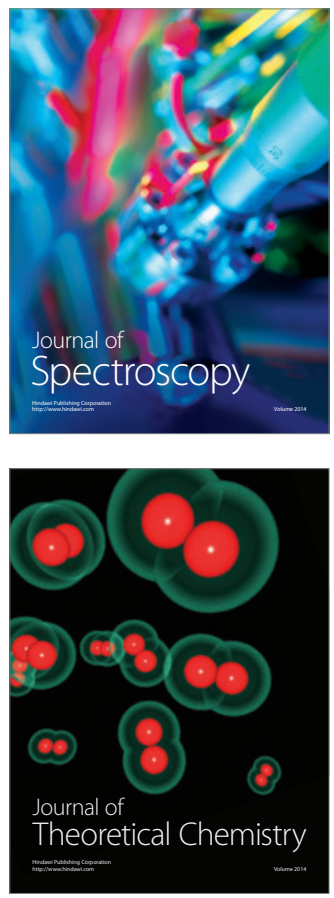
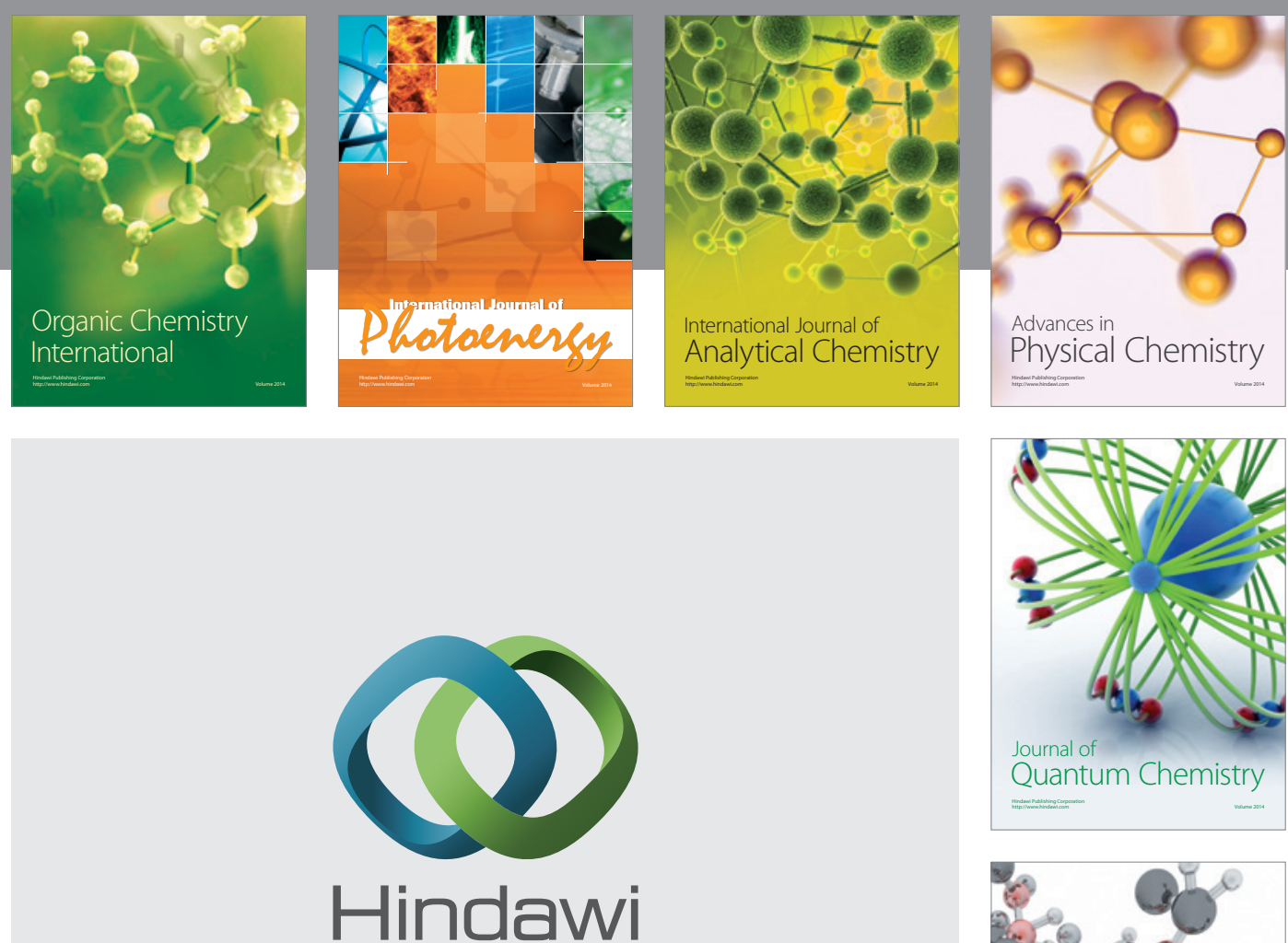

Submit your manuscripts at

http://www.hindawi.com

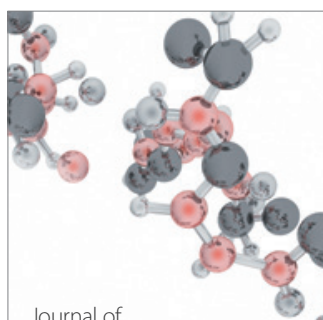

Analytical Methods

in Chemistry

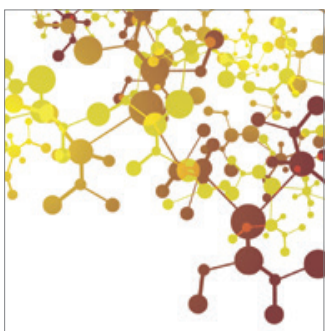

Journal of

Applied Chemistry

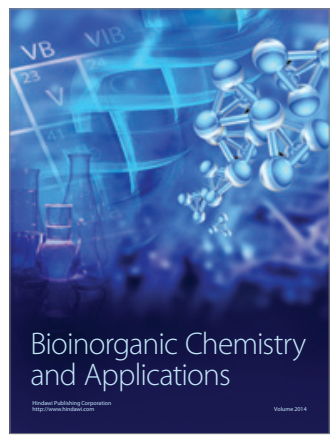

Inorganic Chemistry
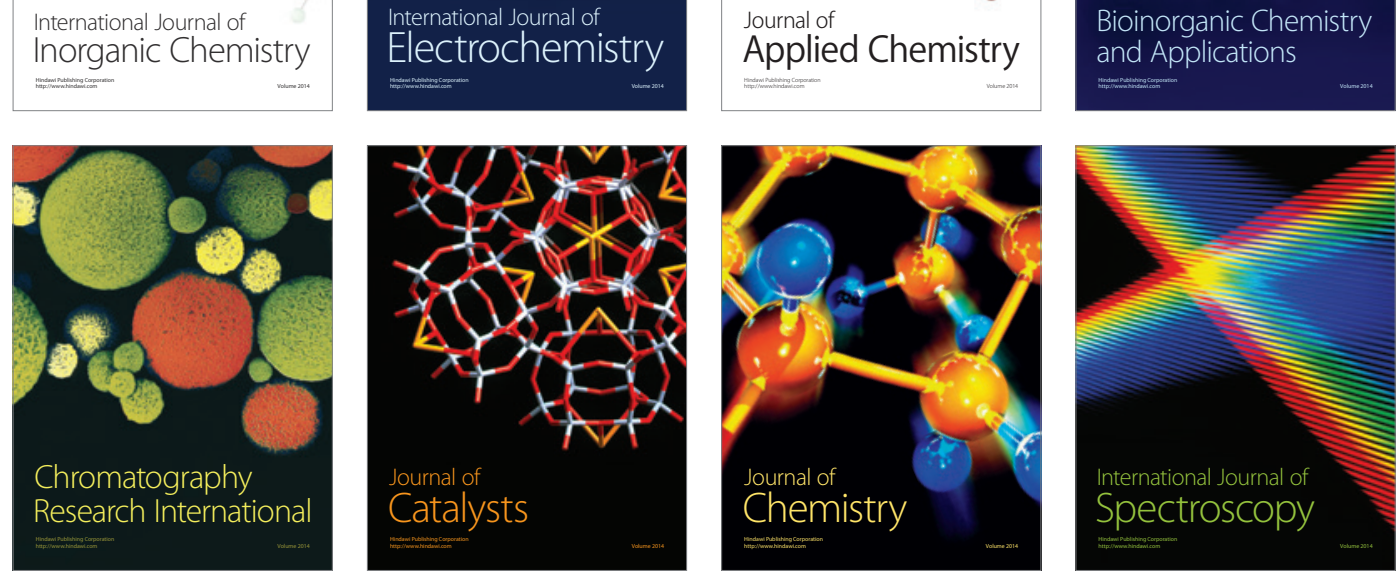